\title{
The educational gradient in cardiovascular risk factors: impact of shared family factors in 228,346 Norwegian siblings
}

\author{
Inger Ariansen ${ }^{1 *}$, Laust Hvas Mortensen², Sidsel Graff-Iversen ${ }^{1,3}$, Hein Stigum 1,4,
} Marte Karoline Råberg Kjøllesdal ${ }^{4}$ and Øyvind Næss ${ }^{1,4}$

\begin{abstract}
Background: Various indicators of childhood socioeconomic position have been related to cardiovascular disease (CVD) risk in adulthood. We investigated the impact of shared family factors on the educational gradient in midlife CVD risk factors by assessing within sibling similarities in the gradient using a discordant sibling design.

Methods: Norwegian health survey data (1980-2003) was linked to educational and generational data. Participants with a full sibling in the health surveys (228,346 individuals in 98,046 sibships) were included. Associations between attained educational level (7-9 years, 10-11 years, 12 years, 13-16 years, or $>16$ years) and CVD risk factor levels in the study population was compared with the corresponding associations within siblings.

Results: Educational gradients in risk factors were attenuated when factors shared by siblings was taken into account: A one category lower educational level was associated with 0.7 ( $95 \%$ confidence interval 0.6 to 0.8 ) mm $\mathrm{Hg}$ higher systolic blood pressure (27\% attenuation), 0.4 (0.4 to 0.5$) \mathrm{mmHg}$ higher diastolic blood pressure (30\%), 1.0 (1.0 to 1.1) more beats per minute higher heart rate (21\%), 0.07 (0.06 to 0.07$) \mathrm{mmol} / \mathrm{l}$ higher serum total cholesterol (32\%), 0.2 (0.2 to 0.2) higher smoking level (5 categories) (30\%), 0.15 (0.13 to 0.17 ) kg/m² higher BMl (43\%), and 0.2 (0.2 to 0.2$) \mathrm{cm}$ lower height (52\%). Attenuation increased with shorter age-difference between siblings.

Conclusion: About one third of the educational gradients in modifiable CVD risk factors may be explained by factors that siblings share. This implies that childhood environment is important for the prevention of CVD.
\end{abstract}

Keywords: Socioeconomic position, Education, Cardiovascular disease risk factors, Family study, Siblings

\section{Background}

In high income countries, cardiovascular disease (CVD) risk factors are generally more prevalent among adults with lower socioeconomic position (SEP) [1, 2]. A substantial proportion of the inverse associations between SEP and CVD are driven by the higher prevalence of CVD risk factors by lower SEP [3, 4]. This socioeconomic gradient in CVD represent a potential for disease prevention, and it is of great policy interest to determine which periods during the life course are important for development of the cardiovascular disease risk factors; elevated blood pressure,

\footnotetext{
* Correspondence: inger.ariansen@gmail.com; inger.ariansen@fhi.no ${ }^{1}$ Domain for Mental and Physical Health, Norwegian Institute of Public Health, PO box 4404, Oslo N-0403, Norway

Full list of author information is available at the end of the article
}

disadvantageous serum lipid profile, obesity, tobacco use and physical inactivity $[5,6]$.

Childhood SEP, usually indicated by parental level of education or occupational class, is associated with adult CVD risk factors in several populations [6-10]. Proposed mechanisms for this association include both biological factors such as poor maternal nutrition and health, intrauterine growth retardation, poor growth in early childhood, obesity in adolescence and repeated childhood infections, and include also environmental factors such as health behaviour and psychosocial factors in the family and surroundings $[5,6,10]$. CVD risk factors might track from childhood to adulthood [11], but are also modifiable in adult age. Body height, in contrast, is a stable trait through adult life. In this context, sibling similarity in the educational gradient in height 
might serve as a strong indicator of shared family environment.

Indicators of childhood and adulthood SEP are likely to be highly correlated, and it is difficult to assess their independent effect on CVD risk [12, 13]. An alternative and potentially robust approach is to use a sibling comparison, where a model of the association between attained education and CVD risk factors within siblings can be compared with a cohort model not using the sibling approach [10,12]. Although this approach is not directly comparable with a randomized controlled trial, it makes it possible to ask the question; what would the socioeconomic gradient in cardiovascular risk factors be if everyone experienced similar family environment in childhood. A sibling comparison will control for a number of family factors (genetic and environmental) as a way to quantify the impact of early life on associations between exposures and outcomes in adulthood [10, 12, 14-16]. Studies using this method have reported that part of the educational gradient in adult all-cause and CVD mortality was explained by factors shared by siblings [14-16].

Except for one study by Lawlor et al. analysing the within sibling-effect of education on adult body mass index (BMI) [17], no other studies have to our knowledge investigated the within sibling-effect of education on CVD risk factors. According to that study, the major part of the inverse association between educational attainment and adult BMI may be explained by family factors shared by siblings [17].

We investigated the educational gradient in CVD risk factors between siblings in a large sample from the Norwegian general population, being in their early 40s. We aimed to assess the impact of factors in early life shared by siblings on educational gradient in adulthood CVD risk factors (blood pressure, total cholesterol, heart rate, $\mathrm{BMI}$, smoking).

\section{Methods}

\section{Study population}

Population based health survey participants from the Counties studies (1974-88) [18], the Age 40 Program (1985-1999) and CONOR (1994-2003) [19, 20], born after 1940, turning 40-45 years at the year of their health survey, and who had at least one full sibling among the health survey participants were selected for this sibling design. Participants with missing information for either/both of the parents, missing educational data and participants without any full siblings in the health surveys were excluded (Fig. 1).

The overall participation rate was $86 \%$ for the Counties study [21], 70\% for the Age 40 Program [22] and 58\% for CONOR [19].

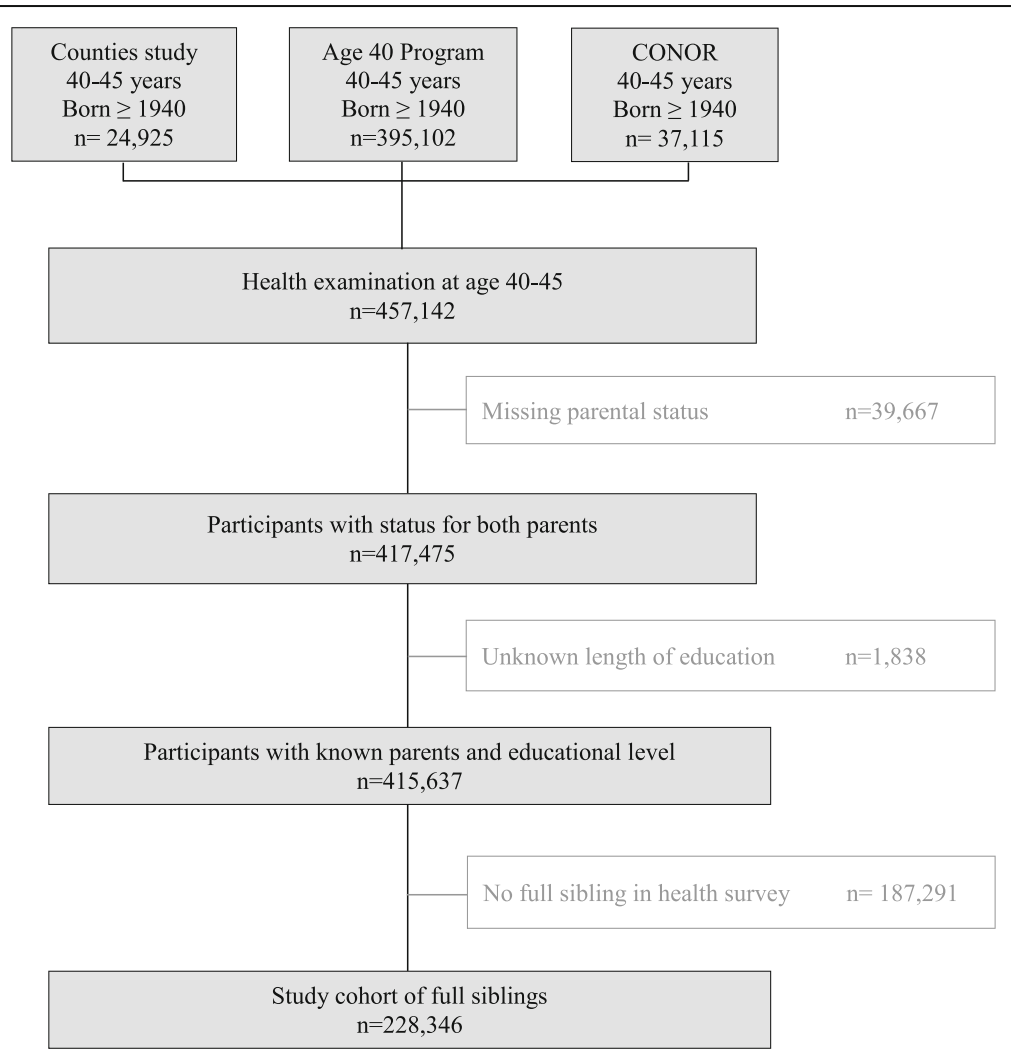

Fig. 1 Participant flow diagram 


\section{Data linkage}

Health survey data were linked to national educational data, to the Norwegian Population Registry, and to the Norwegian Family Based Life Course (NFLC) study [23] using the unique national personal identification number.

\section{Generational data}

The index person's mother, father and siblings were identified from the NFLC study [23]. Parental identification has been proven to be reliable for index persons born from 1940 and onwards [23]. Full siblings were defined as persons registered with the same mother and father in the NFLC study. Twins were included.

\section{Education}

Education was registered in the National Educational Database and reported in National Population and Housing Censuses every $10^{\text {th }}$ year from $1970-2001$. A person's highest attained educational level was classified as up to 9 years, [or 7 years in the 1960s], 10-11 years, 12 years (or vocational education with corresponding academic level), 13-16 years, and more than 16 years. Participants with no registered education were excluded.

\section{Cardiovascular risk factors}

In all health surveys self-assessed questionnaires, clinical measures and non-fasting blood sampling were collected [18-20]. Smoking status and cigarette pack years were collapsed into a graded variable; 1 ) never smoker, 2) past smoker with $<20$ pack years, 3) past smoker with $\geq 20$ pack years, 4) current smoker with $<20$ pack years, 5) current smoker with $\geq 20$ pack years. Self-reported treatment with blood pressure lowering medications was recorded. Blood pressure was initially measured manually by sphygmomanometers (Ercameter, ERKA, Bad Tölz, Germany), and the second of two measurements defined systolic and diastolic blood pressure. Later, the average of the last two available automatic oscillometric measures (Dinamap, Criticon, Tampa, USA) [24] defined blood pressure. Heart rate, as a proxy for physical activity [25], was recorded during the automatic blood pressure measurements which were performed after $2 \mathrm{~min}$ of rest [24]. Height and weight were measured and BMI $\left(\mathrm{kg} / \mathrm{m}^{2}\right)$ was calculated. Non-fasting serum total cholesterol were initially measured by non-enzymatic, and later enzymatic method, and the non-enzymatic values were converted by a correction factor [26]. Systematic COronary Risk Evaluation (SCORE) risk prediction score of 10-year CVD mortality was calculated based on our variables; age, sex, systolic blood pressure, total cholesterol and current daily smoking. We applied the algorithm presented in Appendix A in the paper by Conroy et al. and chose the coefficients for CVD risk in a high risk population [27].

\section{Statistical analyses}

Descriptive statistics are presented as mean \pm standard deviation (SD) and as counts of persons (\%). The Cuzick test for trend was used. Multilevel linear regressions of the exposure education was fitted in separate models for each of the outcomes; systolic blood pressure, diastolic blood pressure, heart rate, total cholesterol, BMI, height, smoking category and the SCORE risk score. The analyses were adjusted for sex, age at examination and examination year. The cohort estimate assesses the association between all individuals regardless of sibling similarities. In the within sibship estimate, each individual together with their sibling(s) made up a sibship cluster. The individual-specific factors that are constant in siblings (shared genes or familial environment) are omitted in the within sibships estimate. In addition, the within sibships term control for confounding from unobserved family-level factors. The dissimilarity of the association between education and the CVD risk factor for the cohort and the within sibships estimates was tested by using the Hausman specification test [28].

Evaluation of the dissimilarity between the cohort and within sibship estimates helps interpret the role of shared family factors. If the between- and withinassociations are equal, it indicates that the unobserved family-specific factors in the within sibships analyses are not important. A weaker within sibships association than cohort association may indicate that these unmeasured family factors confound parts of the association. A stronger within sibships association may indicate that these unmeasured factors have obscured the association [28]. One example could be; among 4 siblings with different attained educational level, all overweight with a slightly lower BMI for the ones with higher educational level, there is a weaker within sibships educational gradient in BMI than among unrelated individuals in a cohort. If numerous sibships had such weaker gradients, the attenuation of the educational BMI gradient from the cohort analyses to the within sibships analyses would suggest that unmeasured family factors confound the association between educational level and BMI.

Variability expressed as SD in CVD risk factors between individuals in the cohort and within the sibships was assessed. The regression beta coefficient ( $\beta$ ) represents the number of units more disadvantageous CVD risk factor per one lower educational level. The percentage change from the $\beta_{\text {Cohort }}$ to the $\beta_{\text {Within sibships }}$ was expressed as: $\%=\left(\left(\beta_{\text {Cohort }}-\beta_{\text {Within sibships }}\right) / \beta_{\text {Cohort }}\right)^{* 100 \text {. In a }}$ sub-population of sibships with only two siblings, we stratified the population by age-difference between siblings.

Assumptions were examined in the cohort models by standard linear regression, for which diagnostic statistical tests are available. Potential deviations from linearity or non-constant variance were examined in plots of 
residuals against predicted values. Robustness was examined by plotting delta beta values against the participants' reference numbers to look for points with high influence, and by plotting leverage-versus-squaredresidual plots. We examined whether the cohort models gave negative predictions.

Sensitivity analyses were performed: We examined interaction between education and sex in the cohort models. We stratified the analyses by sex which meant that only same-sex siblings contributed. Also, the analyses were performed in a sub-population including only sibships with discordant educational level. The statistical package STATA version 13 was used.

\section{Results}

Study population

Of the 457,142 health survey participants born in 1940 and forth, and examined the year they turned $40-45$ years, 91\% had information on parental status from the NFLC study, while 39,667 individuals (9\%) were excluded due to missing parental status (Fig. 1). The educational level was lower for those with missing parental status (21.7\% basic education) than for those with registered parental status $(16.3 \%$ basic education, $p<0.001$ ). Of the participants with registered parental status $0.4 \%$ had unregistered length of education and were excluded from the analyses (Fig. 1). These excluded participants had similar mean percentage points

Table 1 Characteristics of the study cohort

\begin{tabular}{|c|c|c|c|c|c|c|c|}
\hline & \multirow[t]{2}{*}{ All educational levels } & \multicolumn{6}{|c|}{ Years of attained education } \\
\hline & & $7-9$ & $10-11$ & 12 & $13-16$ & $>16$ & $\mathrm{p}$ trend \\
\hline \multicolumn{8}{|l|}{ Men } \\
\hline Participants, n (\%) & 110,528 & $18,348(17)$ & $34,889(32)$ & $31,351(28)$ & $18,593(17)$ & $7,347(7)$ & \\
\hline Age at examination, mean \pm SD (years) & $41.5 \pm 1.1$ & $41.5 \pm 1.2$ & $41.5 \pm 1.1$ & $41.4 \pm 1.1$ & $41.5 \pm 1.1$ & $41.6 \pm 1.2$ & \\
\hline Year of birth, mean & 1951 & 1950 & 1951 & 1952 & 1952 & 1951 & \\
\hline Systolic blood pressure, mean \pm SD (mmHg) & $134 \pm 13$ & $135 \pm 14$ & $134 \pm 14$ & $133 \pm 13$ & $132 \pm 13$ & $132 \pm 13$ & $<0.001$ \\
\hline Diastolic blood pressure, mean $\pm \mathrm{SD}(\mathrm{mmHg})$ & $80 \pm 10$ & $81 \pm 10$ & $80 \pm 10$ & $79 \pm 10$ & $79 \pm 10$ & $79 \pm 9$ & $<0.001$ \\
\hline Heart rate, mean \pm SD (beats/min) & $72 \pm 13$ & $75 \pm 13$ & $73 \pm 13$ & $72 \pm 12$ & $70 \pm 12$ & $69 \pm 12$ & $<0.001$ \\
\hline Total cholesterol, mean \pm SD $(\mathrm{mmol} / \mathrm{l})$ & $5.8 \pm 1.1$ & $6.0 \pm 1.2$ & $5.9 \pm 1.1$ & $5.8 \pm 1.1$ & $5.7 \pm 1.0$ & $5.6 \pm 1.0$ & $<0.001$ \\
\hline $\mathrm{BMI}$, mean $\pm \mathrm{SD}\left(\mathrm{kg} / \mathrm{m}^{2}\right)$ & $25.7 \pm 3.2$ & $26.0 \pm 3.5$ & $25.8 \pm 3.3$ & $25.8 \pm 3.1$ & $25.3 \pm 2.9$ & $24.9 \pm 2.8$ & $<0.001$ \\
\hline Height, mean \pm SD $(\mathrm{cm})$ & $179 \pm 6$ & $178 \pm 6$ & $179 \pm 6$ & $179 \pm 6$ & $180 \pm 6$ & $181 \pm 6$ & $<0.001$ \\
\hline Daily smokers, n (\%) & $44,063(40)$ & $9,998(55)$ & $15,637(45)$ & $12,412(40)$ & $4,877(26)$ & $1,139(16)$ & $<0.001$ \\
\hline $\begin{array}{l}\text { SCORE } 10 \text { year CVD mortality risk score, } \\
\text { mean } \pm \text { SD (percentage points) }\end{array}$ & $1.1 \pm 0.7$ & $1.3 \pm 0.8$ & $1.2 \pm 0.7$ & $1.1 \pm 0.6$ & $0.9 \pm 0.6$ & $0.9 \pm 0.5$ & $<0.001$ \\
\hline Antihypertensive treatment, n (\%) & $2,499(2.3)$ & $566(3.1)$ & $866(2.5)$ & $657(2.1)$ & $323(1.7)$ & $87(1.1)$ & $<0.001$ \\
\hline Myocardial infarction, stroke and/or diabetes, n (\%) & $1,572(1.4)$ & $401(2.2)$ & $506(1.5)$ & $411(1.3)$ & $216(1.2)$ & $38(0.5)$ & $<0.001$ \\
\hline \multicolumn{8}{|l|}{ Women } \\
\hline Participants, n (\%) & $117,818(100)$ & $21,292(18)$ & $52,487(45)$ & $17,161(15)$ & $24,793(21)$ & $2,085(2)$ & \\
\hline Age at examination, mean \pm SD (years) & $41.5 \pm 1.1$ & $41.5 \pm 1.1$ & $41.5 \pm 1.1$ & $41.4 \pm 1.1$ & $41.5 \pm 1.2$ & $41.6 \pm 1.2$ & \\
\hline Year of birth, mean & 1952 & 1950 & 1951 & 1952 & 1952 & 1952 & \\
\hline Systolic blood pressure, mean $\pm \mathrm{SD}(\mathrm{mmHg})$ & $124 \pm 14$ & $127 \pm 15$ & $125 \pm 14$ & $123 \pm 14$ & $122 \pm 13$ & $121 \pm 13$ & $<0.001$ \\
\hline Diastolic blood pressure, mean $\pm \mathrm{SD}(\mathrm{mmHg})$ & $75 \pm 10$ & $77 \pm 10$ & $75 \pm 10$ & $74 \pm 10$ & $73 \pm 10$ & $73 \pm 9$ & $<0.001$ \\
\hline Heart rate, mean \pm SD (beats/min) & $77 \pm 12$ & $80 \pm 13$ & $77 \pm 12$ & $76 \pm 12$ & $75 \pm 12$ & $74 \pm 12$ & $<0.001$ \\
\hline Total cholesterol, mean \pm SD $(\mathrm{mmol} / \mathrm{l})$ & $5.5 \pm 1.0$ & $5.7 \pm 1.1$ & $5.5 \pm 1.0$ & $5.4 \pm 1.0$ & $5.3 \pm 0.9$ & $5.2 \pm 0.9$ & $<0.001$ \\
\hline $\mathrm{BMI}$, mean $\pm \mathrm{SD}\left(\mathrm{kg} / \mathrm{m}^{2}\right)$ & $24.3 \pm 3.9$ & $24.7 \pm 4.2$ & $24.5 \pm 3.9$ & $24.4 \pm 3.8$ & $23.9 \pm 3.4$ & $23.3 \pm 3.1$ & $<0.001$ \\
\hline Height, mean \pm SD $(\mathrm{cm})$ & $166 \pm 6$ & $165 \pm 6$ & $166 \pm 6$ & $166 \pm 6$ & $167 \pm 6$ & $168 \pm 6$ & $<0.001$ \\
\hline Daily smokers, n (\%) & $47,255(40)$ & $12,289(58)$ & $22,822(44)$ & $6,427(37)$ & $5,408(22)$ & $309(15)$ & $<0.001$ \\
\hline $\begin{array}{l}\text { SCORE } 10 \text { year CVD mortality risk score, } \\
\text { mean } \pm \text { SD (percentage points) }\end{array}$ & $0.16 \pm 0.11$ & $0.20 \pm 0.14$ & $0.16 \pm 0.10$ & $0.15 \pm 0.09$ & $0.13 \pm 0.08$ & $0.12 \pm 0.07$ & $<0.001$ \\
\hline Antihypertensive treatment, n (\%) & $2,168(1.8)$ & $563(2.7)$ & $1,028(2.0)$ & $287(1.7)$ & $275(1.1)$ & $15(0.7)$ & $<0.001$ \\
\hline Myocardial infarction, stroke, and/or diabetes, n (\%) & $1,044(0.9)$ & $226(1.1)$ & $484(0.9)$ & $150(0.9)$ & $174(0.7)$ & $10(0.5)$ & $<0.001$ \\
\hline
\end{tabular}

$\mathrm{N}(\%)$ is number of individuals (in proportion of all individuals). SD is standard deviation. CVD is cardiovascular disease. SCORE is the Systematic COronary Risk Evaluation risk prediction score of 10 -year cardiovascular mortality 
SCORE risk score $(0.59 \pm 0.62 \mathrm{SD})$ as the included participants with registered length of education $(0.62$ $\pm 0.70), p=0.496$. Of the participants with registered parental status and registered length of education $45 \%$ did not have a full sibling in the health surveys and were excluded from the analyses (Fig. 1). For these excluded participants a lower proportion had basic education (15.1\%) than for the included participants (17.4\%), $p<0.001$.

In all, 228,346 participants had a full sibling that had participated in one of the health surveys, and they defined the study population (Fig. 1).

\section{Descriptive analyses}

The study population included 117,818 (52\%) women and 110,528 (48\%) men who were born from 1940-1963 and examined in 1980-2003 at median age 41 years. Only $1.2 \%$ of the study cohort had missing values for any of the CVD risk factors.

The study population of 228,346 participants made up 98,046 sibships that included up to 9 siblings. Of the sibships, $73 \%$ consisted of two siblings, $20 \%$ consisted of three siblings, and $6 \%$ consisted of four or more siblings. In all 164, 518 participants (72\%) were parts of sibling groups with differing educational level between two or more siblings.

More disadvantageous CVD risk factor levels were found by lower levels of education in men and women (Table 1). Smaller variation and thus more similarity in CVD risk factors were found within sibships than between all individuals in the cohort (Table 2).

Table 2 Variation in educational level and cardiovascular risk factors within sibships and between individuals in the cohort

\begin{tabular}{lccc}
\hline & $\begin{array}{c}\text { Cohort } \\
\text { Mean level }\end{array}$ & $\begin{array}{l}\text { Cohort } \\
\text { Standard } \\
\text { deviation }\end{array}$ & $\begin{array}{c}\text { Within sibships } \\
\text { Standard } \\
\text { deviation }\end{array}$ \\
\hline Educational level (1-5 levels) & 2.5 & \pm 0.9 & \pm 0.7 \\
$\begin{array}{l}\text { Systolic blood pressure } \\
\text { (mmHg) }\end{array}$ & 129 & \pm 13 & \pm 6 \\
$\begin{array}{l}\text { Diastolic blood pressure } \\
\text { (mmHg) }\end{array}$ & 77 & \pm 9 & \pm 5 \\
Heart rate (beats/min) & 75 & \pm 12 & \pm 5 \\
Total cholesterol (mmol/l) & 5.6 & \pm 0.9 & \pm 0.6 \\
BMl (kg/m ${ }^{2}$ ) & 25.0 & \pm 3.1 & \pm 1.8 \\
Height (cm) & 172 & \pm 8 & \pm 4 \\
Daily smoking (daily smoking & 0.4 & \pm 0.4 & \pm 0.2 \\
coded as 0-1) & & & \\
SCORE (percentage points) & 0.6 & \pm 0.7 & \pm 0.2
\end{tabular}

Educational levels 1-5: (1) up to 7-9 years; (2) 10-11 years; (3) 12 years (4) $13-16$ years; (5) $>16$ years

SCORE is the Systematic COronary Risk Evaluation risk prediction score of 10-year cardiovascular mortality

\section{Cohort and within sibling analyses}

The cohort and within sibships analyses differed significantly by Hausman specification test by $p<0.001$ for all CVD risk factors in Table 3. In the within sibships analyses the educational gradients were attenuated; by one third for blood pressure, total cholesterol, smoking category and SCORE risk score, by two fifths for BMI, by one fifth for heart rate, and by one half for the opposite gradient in adult height (Table 3).

In a subsample of sibships with only two siblings, analyses stratified for age-difference within a sibling pair indicated that a relatively larger proportion of the educational gradient in most of the CVD risk factors was explained by sibling similarities between siblings forin the sibling pairs born closer in time than for the sibling pairs with larger age-span (Table 4).

We found no important deviations from linearity, nor any important non-constant variance of residuals, nor any points with undue high influence. Negative predictions were found only for SCORE risk prediction score, and with no more than $7 \%$ negative predictions.

\section{Sensitivity analyses}

Sex-stratified analyses included 73,023 sisters in 33,602 sibships and 65,400 brothers in 30,209 sibships, and showed a similar pattern as the main results. We did not formally test the sex differences in the estimates; however the educational gradients for blood pressure, total cholesterol and BMI in women were numerically stronger than in men (Additional file 1: Tables A and B). Analyses performed in the sub-population of only sibhips discordant for educational attainment showed similar pattern as in the main analyses (Additional file 1: Table C vs. Table 3).

\section{Discussion}

In this study on average one third of the inverse educational gradients in blood pressure, serum total cholesterol, smoking, heart rate and BMI were explained by family factors shared by siblings. Furthermore, these educational gradients were explained to a greater extent with closer age-span between siblings.

The main strength of this study is the large sample size with clinical measurements, sex-stratified analyses, and the consistency of our finding across a wide range of CVD risk factors. The narrow age range of 40-45 years makes the risk factor levels comparable between siblings. The strict definition of siblings (with same mother and father) increases the plausibility of similar childhood environment and proportion of common genes. Also, the divorce rate was below $0.4 \%$ per year during 1940-1970 [29]. A potential weakness of the within sibships analysis is that it conditions on sibships discordant for education and CVD risk factors. This 
Table 3 Cardiovascular risk factor levels according to level of education in the cohort and within sibships

\begin{tabular}{|c|c|c|c|c|c|c|c|c|}
\hline \multirow{2}{*}{$\begin{array}{l}\text { Education } \\
\text { Years }\end{array}$} & \multirow{2}{*}{$\begin{array}{l}\text { Cohort } \\
\beta_{\text {Cohort }}(95 \% \text { Cl) }\end{array}$} & \multirow{2}{*}{$\begin{array}{l}\text { Within sibships } \\
\beta_{\text {Within sibships }}(95 \% \mathrm{Cl})\end{array}$} & \multicolumn{2}{|l|}{ Difference } & \multirow{2}{*}{$\begin{array}{l}\text { Cohort } \\
\beta_{\text {Cohort }}(95 \% \text { Cl) }\end{array}$} & \multirow{2}{*}{$\begin{array}{l}\text { Within sibships } \\
\beta_{\text {Within sibships }}(95 \% \mathrm{Cl})\end{array}$} & \multicolumn{2}{|l|}{ Difference } \\
\hline & & & $\beta_{\Delta}(95 \% \mathrm{Cl})$ & $\%$ & & & $\beta_{\Delta}(95 \% \mathrm{Cl})$ & $\%$ \\
\hline & \multicolumn{4}{|c|}{ Systolic blood pressure $(\mathrm{mmHg})$} & \multicolumn{2}{|c|}{ Diastolic blood pressure (mmHg) } & & \\
\hline 7-9 & $3.6(3.2,3.9)$ & $2.5(2.0,2.9)$ & & & $2.1(1.9,2.3)$ & $1.4(1.1,1.7)$ & & \\
\hline $10-11$ & $2.3(2.0,2.6)$ & $1.6(1.2,2.0)$ & & & $1.2(1.0,1.4)$ & $0.8(0.5,1.0)$ & & \\
\hline 12 & $1.6(1.3,1.9)$ & $1.0(0.6,1.4)$ & & & $0.7(0.5,0.9)$ & $0.4(0.1,0.7)$ & & \\
\hline $13-16$ & $0.2(-0.1,0.5)$ & $-0.0(-0.4,0.4)$ & & & $0.1(-0.1,0.3)$ & $-0.0(-0.3,0.2)$ & & \\
\hline$>16$ & 0 & 0 & & & 0 & 0 & & \\
\hline Per lower level & $1.0(0.9,1.0)$ & $0.7(0.6,0.8)$ & $0.3(0.2,0.3)$ & -27 & $0.6(0.5,0.6)$ & $0.4(0.4,0.5)$ & $0.2(0.1,0.2)$ & \\
\hline
\end{tabular}

Total cholesterol, $(\mathrm{mmol} / \mathrm{l})$

$\begin{array}{lcc}7-9 & 0.38(0.36,0.41) & 0.24(0.22,0.28) \\ 10-11 & 0.26(0.24,0.28) & 0.19(0.16,0.22) \\ 12 & 0.20(0.18,0.22) & 0.13(0.10,0.16) \\ 13-16 & 0.07(0.05,0.09) & 0.04(0.02,0.07) \\ >16 & 0 & 0\end{array}$

Per lower level $\quad 0.10(0.09,0.10) \quad 0.07(0.06,0.07)$

Body mass index, $\left(\mathrm{kg} / \mathrm{m}^{2}\right)$

$\begin{array}{lcc}7-9 & 1.14(1.06,1.21) & 0.61(0.51,0.72) \\ 10-11 & 0.88(0.80,0.95) & 0.49(0.39,0.59) \\ 12 & 0.77(0.69,0.84) & 0.45(0.35,0.55) \\ 13-16 & 0.31(0.23,0.38) & 0.11(0.02,0.21) \\ >16 & 0 & 0 \\ \text { Per lower level } & 0.27(0.25,0.28) & 0.15(0.13,0.17) \\ & & \\ & \text { Smoking status and pack years (category) } \\ 7-9 & 1.30(1.27,1.34) & 0.91(0.86,0.95) \\ 10-11 & 0.96(0.93,0.99) & 0.71(0.67,0.75) \\ 12 & 0.81(0.78,0.84) & 0.58(0.53,0.62) \\ 13-16 & 0.34(0.31,0.37) & 0.25(0.21,0.29) \\ >16 & 0 & 0\end{array}$

Per lower level $0.31(0.30,0.31) \quad 0.22(0.21,0.22)$

Heart rate (beats/min)

$\begin{array}{cc}5.4(5.1,5.6) & 4.2(3.8,4.6) \\ 3.6(3.3,3.9) & 2.9(2.6,3.3) \\ 2.6(2.3,2.9) & 2.2(1.8,2.5) \\ 1.2(0.9,1.5) & 0.9(0.5,1.3) \\ 0 & 0 \\ 1.3(1.3,1.4) & 1.0(1.0,1.1)\end{array}$

$0.03(0.03,0.04) \quad-32 \quad 1.3(1.3,1.4)$

$1.0(1.0,1.1)$

$0.3(0.2,0.3) \quad-21$

Height $(\mathrm{cm})$

$$
\begin{array}{ll}
-2.1(-2.2,-1.9) & -1.0(-1.2,-0.9) \\
-1.5(-1.6,-1.4) & -0.8(-1.0,-0.7) \\
-1.3(-1.4,-1.2) & -0.7(-0.8,-0.6) \\
-0.7(-0.8,-0.6) & -0.4(-0.5,-0.3)
\end{array}
$$

0

0 $0.12(0.10,0.13) \quad-43$

$-0.4(-0.5,-0.4)$

$-0.2(-0.2,-0.2)$

$-0.2(-0.2,-0.2) \quad 52$

SCORE (percentage points)

$\begin{array}{cc}0.31(0.30,0.32) & 0.23(0.22,0.25) \\ 0.24(0.23,0.25) & 0.20(0.18,0.21) \\ 0.20(0.19,0.21) & 0.16(0.15,0.18) \\ 0.13(0.12,0.14) & 0.12(0.10,0.13) \\ 0 & 0\end{array}$

$0.09(0.09,0.10) \quad-30 \quad 0.06(0.06,0.07)$

$0.05(0.04,0.05)$

$0.02(0.02,0.02) \quad-30$

$\beta$ is the beta regression coefficient. $95 \% \mathrm{Cl}$ is $95 \%$ confidence interval. $\beta \Delta=\beta_{\text {Cohort }}-\beta_{\text {Within sibships. } \%}=\left(\left(\beta_{\text {Cohort }}-\beta_{\text {Within sibships }}\right) / \beta_{\text {cohort }}\right)^{*} 100$. Educational levels 1-5: (1) up to 7-9 years; (2) 10-11 years; (3) 12 years (4) 13-16 years; (5) >16 years. Smoking status and pack years categories 1-5: (1) never smoker, (2) past smoker and $<20$ pack-years, (3) past smoker and $>20$ pack-years, (4) current smoker and $<20$ pack-years, (5) current smoker and $>20$ pack-years). SCORE is the Systematic COronary Risk Evaluation risk prediction score of 10-year cardiovascular mortality. All analyses are adjusted for age at examination and examination year, both centred on median, and for sex. Analyses of blood pressure are adjusted for current antihypertensive treatment. The Hausman specification tests for difference between the cohort and within sibships effect estimates was significant $p<0.001$ for all cardiovascular risk factors

implies a selection of sibships that might differ in nonshared causes of the educational level attained and of the measured CVD risk factor level [30]. Non-shared environment include systematic elements such as birth order and birth year that might introduce non-shared confounding [10]. Our results were not altered when adjusting for birth order (results not shown), stratifying the analyses by sex, or restricting the analyses to sibships discordant for educational level (Additional file 1). Non- systematic non-shared environment that we did not take into account (season of birth, sibling-sibling interactions, differential parental treatment and peer groups) might also have contributed to non-shared confounding [10]. Our analyses were strengthened by including adult height, which is a composite measure of genetic disposition, health and nutrition during the growing years [31], is potentially modifiable during early life up to puberty where most siblings share environment, and is unlikely to 


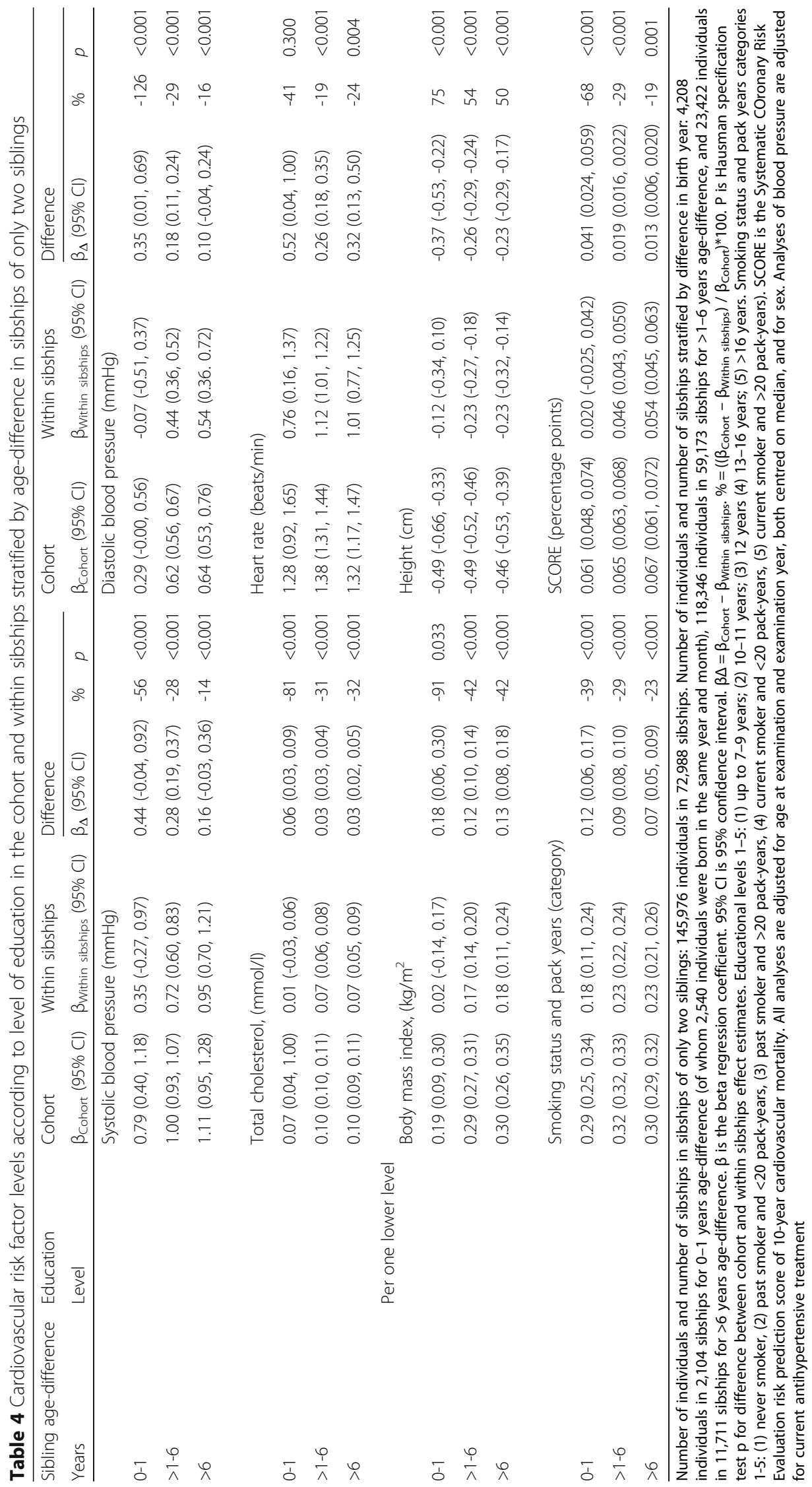


be causally affected by attained education unlike the other CVD risk factors examined in this paper. Accordingly, shared family factors had the strongest impact on the educational gradient in height, of all the CVD risk factor gradients (Table 3). Our sibling design has thus the potential to capture unobserved shared confounding, as the educational gradient in height that is not explained by shared family factors might result from residual confounding from non-shared factors in early life, childhood and youth.

Our findings are consistent with the one previous study by Lawlor et al [17], comparing the associations between educational attainment and BMI within siblings of the same family and between individuals form different families in a smaller study comprising 5467 individuals. Here the effect of education on adult BMI between individuals from different families was attenuated to the null in within sibling pair analyses.

The sibling similarities in the educational gradients in the modifiable midlife CVD risk factors, blood pressure, serum total cholesterol, smoking, heart rate and BMI, that we identify (Table 3), can be interpreted as a result of both the environment that siblings share; parents' health behaviour, parents' socioeconomic position, housing, neighbourhood and schooling, in addition to genes that full siblings share (approximately 50\% [10]). These shared family similarities were weakened by a larger agespan between siblings (Table 4). This is in agreement with siblings with longer age-span sharing the same proportion of genes, but to a lesser extent their childhood environment than sibling pairs born closer in time [10], and suggests that family environment plays an important role in the socioeconomic gradient in CVD.

\section{Conclusions}

Around one third of the association between lower educational attainment and less favourable risk factors seem to be explained by shared family factors. The contribution increases with shorter age-difference between siblings. This suggests that there is substantial scope for prevention of CVD that starts early and that childhood environment matters.

\section{Additional file}

Additional file 1: Table A Cardiovascular risk factor levels according to level of education in the cohort and within sibships in men. Table B Cardiovascular risk factor levels according to level of education in the cohort and within sibships in women. Table $\mathbf{C}$ Cardiovascular risk factor levels according to level of education in the cohort and within sibships in sibships discordant for educational level. (DOCX 46 kb)

\section{Abbreviations}

BMl: Body mass index; CVD: Cardiovascular disease; NFLC study: The Norwegian family based life course study; SCORE: Systematic COronary risk evaluation; SD: Standard deviation; SEP: Socioeconomic position; $\beta$ : Beta regression coefficient

\section{Acknowledgements}

We acknowledge senior researcher Randi Selmer at the Norwegian Institute of Public Health for sharing knowledge on calculation of the SCORE risk score. The interpretation and reporting of these data is the sole responsibility of the authors, and no endorsement by the Norwegian Cause of Death Registry is intended nor should be inferred.

\section{Funding}

This work was supported by the Norwegian Research Council [Grant number 213788].

\section{Availability of data and materials}

The dataset analyzed during the current study is not available due to restrictions in the permission given by the Regional Ethics Committee South-East.

\section{Authors' contributions}

$\varnothing \mathrm{N}$ conceived the study, acquired the data and handled supervision. IA, LHM, SG-I, HS and ØN participated in the design of the study. IA, LHM, HS, MKRK and $\varnothing \mathrm{N}$ participated in the analyses and interpretation of the data. IA drafted the manuscript. LHM, SG-I, HS, MKRK and ØN made critical revisions of the manuscript for key intellectual content, and all authors have read and approved the final manuscript.

\section{Competing interests}

The authors declare that they have no competing interests.

\section{Consent for publication}

Not applicable.

\section{Ethics approval and conset to participate}

The data linkage was approved by the Regional Ethics Committee South-East in May 25 $5^{\text {th }}$ 2012, reference number 2012/872, and the study complies with the Declaration of Helsinki.

Written informed consent was obtained from participants in the Age 40 Program and CONOR. Participants in the Counties studies gave written permission for their results to be sent to their physician. Permission to be absolved from this professional secrecy has been granted and concession to handle this personal health information has been given by the authorities.

\section{Author details}

${ }^{1}$ Domain for Mental and Physical Health, Norwegian Institute of Public Health, PO box 4404, Oslo N-0403, Norway. ${ }^{2}$ Section of Social Medicine, University of Copenhagen, PO box 2099, Copenhagen K 1014, Denmark. ${ }^{3}$ Department of Community Medicine, The Arctic University of Norway, Tromsø, Norway. ${ }^{4}$ Institute of Health and Society, University of Oslo, PO box 1130, Oslo 0318, Norway.

Received: 13 January 2016 Accepted: 9 February 2017 Published online: 30 March 2017

\section{References}

1. Stringhini S, Dugravot A, Shipley M, Goldberg M, Zins M, Kivimaki M, Marmot M, Sabia S, Singh-Manoux A. Health behaviours, socioeconomic status, and mortality: further analyses of the British Whitehall $\|$ and the French GAZEL prospective cohorts. PLoS Med. 2011;8(2), e1000419.

2. Kanjilal S, Gregg EW, Cheng YJ, Zhang P, Nelson DE, Mensah G, Beckles GL. Socioeconomic status and trends in disparities in 4 major risk factors for cardiovascular disease among US adults, 1971-2002. Arch Intern Med. 2006:166(21):2348-55.

3. Stringhini S, Sabia S, Shipley M, Brunner E, Nabi H, Kivimaki M, SinghManoux A. Association of socioeconomic position with health behaviors and mortality. JAMA. 2010;303(12):1159-66.

4. Laaksonen M, Talala K, Martelin T, Rahkonen O, Roos E, Helakorpi S, Laatikainen T, Prattala R. Health behaviours as explanations for educational level differences in cardiovascular and all-cause mortality: a follow-up of 60 000 men and women over 23 years. Eur J Public Health. 2008;18(1):38-43. 
5. Harper S, Lynch J, Smith GD. Social determinants and the decline of cardiovascular diseases: understanding the links. Annu Rev Public Health. 2011;32:39-69.

6. Ben-Shlomo Y, Kuhn D. A life course approach to chronic disease epidemiology: conceptual models, empirical challenges and interdisciplinary perspectives. Int J Epidemiol. 2002;31(2):285-93.

7. Galobardes B, Lynch JW, Smith GD. Is the association between childhood socioeconomic circumstances and cause-specific mortality established? Update of a systematic review. J Epidemiol Community Health. 2008;62(5):387-90.

8. Lamont D, Parker L, White M, Unwin N, Bennett S, Cohen M, Richardson D, Dickinson HO, Adamson A, Alberti K. Risk of cardiovascular disease measured by carotid intima-media thickness at age 49-51: lifecourse study. BMJ. 2000;320(7230):273-8

9. Packard CJ, Bezlyak V, McLean JS, Batty GD, Ford I, Burns H, Cavanagh J, Deans KA, Henderson M, McGinty A. Early life socioeconomic adversity is associated in adult life with chronic inflammation, carotid atherosclerosis, poorer lung function and decreased cognitive performance: a crosssectional, population-based study. BMC Public Health. 2011;11(1):42.

10. Smith GD. Epidemiology, epigenetics and the 'Gloomy Prospect': embracing randomness in population health research and practice. International J Epidemiol. 2011;40(3):537-62.

11. Mattsson N, Ronnemaa T, Juonala M, Viikari JS, Raitakari OT. Childhood predictors of the metabolic syndrome in adulthood. The Cardiovascular Risk in Young Finns Study. Ann Med. 2008;40(7):542-52.

12. Gilman SE, Loucks EB. Invited commentary: does the childhood environment influence the association between every $x$ and every $y$ in adulthood? Am J Epidemiol. 2012;176(8):684-8.

13. Galobardes B, Smith GD, Lynch JW. Systematic review of the influence of childhood socioeconomic circumstances on risk for cardiovascular disease in adulthood. Ann Epidemiol. 2006;16(2):91-104

14. Naess O, Hoff DA, Lawlor D, Mortensen LH. Education and adult causespecific mortality - examining the impact of family factors shared by 871 367 Norwegian siblings. Int J Epidemiol. 2012;1-9.

15. Søndergaard G, Mortensen LH, Andersen A-MN, Andersen PK, Dalton SO, Madsen M, Osler M. Does shared family background influence the impact of educational differences on early mortality? Am J Epidemiol. 2012;176(8):675-83.

16. Madsen M, Andersen PK, Gerster M, Andersen AM, Christensen K, Osler M. Are the educational differences in incidence of cardiovascular disease explained by underlying familial factors? A twin study. Soc Sci Med. 2014;118:182-90.

17. Lawlor DA, Clark H, Davey Smith G, Leon DA. Childhood intelligence, educational attainment and adult body mass index: findings from a prospective cohort and within sibling-pairs analysis. Int J Obes. 2006;30(12):1758-65.

18. Bjartveit K, Foss OP, Gjervig T, Lund-Larsen PG. The cardiovascular disease study in Norwegian counties. Background and organization. Acta Med Scand Suppl. 1979;634:1-70.

19. Naess O, Sogaard AJ, Arnesen E, Beckstrom AC, Bjertness E, Engeland A, Hjort PF, Holmen J, Magnus P, Njolstad I. Cohort profile: cohort of Norway (CONOR). Int J Epidemiol. 2008;37(3):481-5.

20. Bjartveit K, Stensvold I, Lund-Larsen P, Gjervig T, Krüger O, Urdal P. Cardiovascular screenings in Norwegian counties. Background and implementation. Status of risk pattern during the period 1986-90 among persons aged 40-42 years in 14 counties. Tidsskr Nor Laegeforen. 1991;111(17):2063.

21. Graff-Iversen S. External female hormones, serum lipids and mortality Population studies of Norwegian women. Oslo: University of Oslo; 2005.

22. Thelle DS, Selmer R, Gjesdal K, Sakshaug S, Jugessur A, Graff-Iversen S, Tverdal A, Nystad W. Resting heart rate and physical activity as risk factors for lone atrial fibrillation: a prospective study of 309540 men and women. Heart. 2013;99(23):1755-60.

23. Naess O, Hoff DA. The Norwegian Family Based Life Course (NFLC) study: data structure and potential for public health research. Int J Public Health 2013;58(1):57-64

24. Lund-Larsen P. Blood pressure measured with a sphygmomanometer and with Dinamap under field conditions-a comparison. Nor Epidemiol. 1997; 7(2):235-41

25. Jensen MT, Suadicani P, Hein HO, Gyntelberg F. Elevated resting heart rate, physical fitness and all-cause mortality: a 16-year follow-up in the Copenhagen Male Study. Heart. 2013;99(12):882-7.

26. Foss OP, Urdal P. Cholesterol for more than 25 years: Could the results be compared throughout all this time? Nor Epidemiol. 2003:13(1):85-8.
27. Conroy R, Pyörälä K, Fitzgerald A, Sans S, Menotti A, De Backer G, De Bacquer D, Ducimetiere $P$, Jousilahti $P$, Keil U. Estimation of ten-year risk of fatal cardiovascular disease in Europe: the SCORE project. Eur Heart J. 2003:24(11):987-1003.

28. Rabe-Hesketh S, Skrondal A. Multilevel and lognitudinal modeling using Stata. Texas: Stata press; 2008.

29. Mamelund S-E, Brunborg H, Noack T. Divorce in Norway 1886-1995 by Calendar Year and Marriage Cohort. Oslo-Kongsvinger: Statistics Norway; 1997.

30. Frisell T, Öberg S, Kuja-Halkola R, Sjölander A. Sibling comparison designs: bias from non-shared confounders and measurement error. Epidemiology. 2012;23(5):713-20.

31. Gunnell D. Can adult anthropometry be used as a 'biomarker' for prenatal and childhood exposures? Int J Epidemiol. 2002;31(2):390-4.

\section{Submit your next manuscript to BioMed Central and we will help you at every step:}

- We accept pre-submission inquiries

- Our selector tool helps you to find the most relevant journal

- We provide round the clock customer support

- Convenient online submission

- Thorough peer review

- Inclusion in PubMed and all major indexing services

- Maximum visibility for your research

Submit your manuscript at www.biomedcentral.com/submit
Biomed Central 